NBER WORKING PAPER SERIES

\title{
MISALLOCATION AND PRODUCTIVITY EFFECTS OF THE SMOOT-HAWLEY TARIFF
}

\author{
Eric W. Bond \\ Mario J. Crucini \\ Tristan Potter \\ Joel Rodrigue \\ Working Paper 18034 \\ http://www.nber.org/papers/w18034
}

\author{
NATIONAL BUREAU OF ECONOMIC RESEARCH \\ 1050 Massachusetts Avenue \\ Cambridge, MA 02138 \\ May 2012
}

Tristan Potter acknowledges financial support through the Vanderbilt Undergraduate Summer Research Program, 2010. The views expressed herein are those of the authors and do not necessarily reflect the views of the National Bureau of Economic Research.

NBER working papers are circulated for discussion and comment purposes. They have not been peerreviewed or been subject to the review by the NBER Board of Directors that accompanies official NBER publications.

(C) 2012 by Eric W. Bond, Mario J. Crucini, Tristan Potter, and Joel Rodrigue. All rights reserved. Short sections of text, not to exceed two paragraphs, may be quoted without explicit permission provided that full credit, including $(\odot)$ notice, is given to the source. 
Misallocation and Productivity Effects of the Smoot-Hawley Tariff

Eric W. Bond, Mario J. Crucini, Tristan Potter, and Joel Rodrigue

NBER Working Paper No. 18034

May 2012

JEL No. E6,F1,F13

\begin{abstract}
$\underline{\text { ABSTRACT }}$
Using a newly created microeconomic archive of U.S. imports at the tariff-line level for 1930-33, we construct industry-level tariff wedges incorporating the input-output structure of U.S. economy and the heterogenous role of imports across sectors of the economy. We use these wedges to show that the average tariff rate of $46 \%$ in 1933 substantially understated the true impact of the Smoot-Hawley (SH) tariff structure, which we estimate to be equivalent to a uniform tariff rate of $70 \%$. We use these wedges to calculate the impact of the Smoot Hawley tariffs on total factor productivity and welfare. In our benchmark parameterization, we find that tariff protection reduced TFP by $1.2 \%$ relative to free trade prior to the Smoot Hawley legislation. TFP fell by an additional 0.5\% between 1930 and 1933 due to Smoot Hawley. We also conduct counterfactual policy exercises and examine the sensitivity of our results to changes in the elasticity of substitution and the import share. A doubling of the substitution elasticities yields a TFP decline of almost $5 \%$ relative to free trade, with an additional reduction due to $\mathrm{SH}$ of $0.4 \%$.
\end{abstract}

Eric W. Bond

Vanderbilt University

Department of Economics

VU Station B \#351819

2301 Vanderbilt Place

Nashville, TN 37235-1819

eric.bond@vanderbilt.edu

Mario J. Crucini

Department of Economics

Vanderbilt University

Box 1819 Station B

Nashville, TN 37235-1819

and NBER

mario.j.crucini@vanderbilt.edu

\author{
Tristan Potter \\ Department of Economics \\ Boston College \\ potter.tristan@gmail.com \\ Joel Rodrigue \\ Vanderbilt University \\ joel.b.rodrigue@vanderbilt.edu
}




\title{
Misallocation and Productivity Effects of the Smoot-Hawley Tariff *
}

\author{
Eric W. Bond, Mario J. Crucini, Tristan Potter and Joel Rodrigue
}

This Version: April 25, 2012

\begin{abstract}
Using a newly created microeconomic archive of U.S. imports at the tariff-line level for 1930-33, we construct industry-level tariff wedges incorporating the input-output structure of U.S. economy and the heterogenous role of imports across sectors of the economy. We use these wedges to show that the average tariff rate of $46 \%$ in 1933 substantially understated the true impact of the Smoot-Hawley ( $\mathrm{SH}$ ) tariff structure, which we estimate to be equivalent to a uniform tariff rate of $70 \%$. We use these wedges to calculate the impact of the Smoot Hawley tariffs on total factor productivity and welfare. In our benchmark parameterization, we find that tariff protection reduced TFP by $1.2 \%$ relative to free trade prior to the Smoot Hawley legislation. TFP fell by an additional 0.5\% between 1930 and 1933 due to Smoot Hawley. We also conduct counterfactual policy exercises and examine the sensitivity of our results to changes in the elasticity of substitution and the import share. A doubling of the substitution elasticities yields a TFP decline of almost $5 \%$ relative to free trade, with an additional reduction due to $\mathrm{SH}$ of $0.4 \%$.
\end{abstract}

Keywords: Hawley-Smoot Tariff, Great Depression, commercial policy, productivity, misallocation, macroeconomic inefficiency.

JEL Codes:

\section{Introduction}

The Smoot-Hawley (SH) tariff of 1930 is the most significant piece of tariff legislation in U.S. history. The legislation is often mentioned for rhetorical effect in the context of tariff debates, perhaps most pointedly by Al Gore as he presented Ross Perot with a framed picture of Senator

*Eric Bond: Department of Economics, Vanderbilt University, email: eric.bond@vanderbilt.edu; Mario J. Crucini: NBER and Department of Economics, Vanderbilt University, email: mario.j.crucini@vanderbilt.edu; Tristan Potter: Department of Economics, Boston College; Joel Rodrigue: Department of Economics, Vanderbilt University, joel.rodrigue@vanderbilt.edu. We thank Cem Karayalcin, Diego Restuccia, Richard Rogerson for comments that substantively improved our paper. We also thank conference participants at the SED 2011 held in Ghent, Belgium and the Conference on Macroeconomics Policy, hosted by Bilgi University in Istanbul, Turkey in 2011. We thank David Schenck for excellent research assistance. 
Smoot and Congressman Hawley on Larry King Live in 1993. This was the time at which the controversial North American Free Trade Agreement (NAFTA) was being debated in Congress. Despite the theatre surrounding the Smoot-Hawley tariff, the scope of the legislation and its economic impact remain poorly understood. Much of what is known about the economic effects of $\mathrm{SH}$ and the foreign retaliation that took place comes from macroeconomic models that focus on the impact of the average tariff on imports. The emerging consensus from this literature is that the tariff war alone could have at most precipitated a moderate recession with a larger impact on international trade, but the quantitative effects would be trivial in comparison to the depth and duration of the Great Depression. Far less is know about the impact of the SH tariffs across U.S. industries, and the resulting potential for sectoral misallocation. Our goal in this paper is to assess the extent of sectoral misallocation, and to develop a measure of their aggregate impact. ${ }^{1}$

The most obvious reason for the lack of study on the effect of sectoral misallocations resulting from the SH tariffs is the complexity of the tariff schedules themselves. The tariff and trade data compiled for the quantitative analysis of this paper is the complete line item data from the Foreign Trade and Navigation of the United States (FTNUS) at three different points in time. The number of individual import line items (tariff lines) typically exceeds 4,000 with ad-valorem-equivalent duties ranging from a few percentage points to almost 300. Even more challenging is the fact that the duties themselves took one of three forms: i) pure ad-valorem, assessed as a percentage of the foreign value imported, ii) specific duties, assessed in nominal U.S. currency units per physical quantity imported or iii) a combination of the two. ${ }^{2}$ The practical implication of this is a high degree of dispersion of effective ad valorem tariff rates across sectors, and significant movements in both the mean and variance of those rates over time due to a combination of legislative changes and price-induced changes in the ad valorem equivalent of specific duties.

The impact of both legislative and price-induced variation is evident even at the level of the commonly used aggregate tariff index computed as the ratio of customs revenue to total dutiable imports. Figure 1 shows this measure of the aggregate U.S. tariff rate annually from 1914 to 1940 and identifies the dates of three key pieces of tariff legislation. The first is the Emergency Tariff Act of 1921 which was quickly followed by the Fordney-McCumber Tariff Act of 1922. Combined, these two pieces of legislation led to a sharp rise in the tariff index from its historical trough in 1920. The third notation in the figure is the date the SH tariff schedules went into effect, June 17, 1930. The increase relative to 1929 is evident, though smaller in percentage terms than the increases of the early 1920s. Note, however, the aggregate tariff measure increases from

\footnotetext{
${ }^{1}$ Irwin (2011) provides an excellent discussion of the political process that led to the passage of the SH legislation. Our analysis will focus on the impact of the legislation, taking the process that generated it as a given.

${ }^{2}$ During the period of this study, the United States did not have much in the way of preferential tariffs, and did not use quantitative restrictions on imports.
} 
44.7\% in 1930 to 59\% in 1932 despite the absence of additional legislative changes. Prior research suggests that much of the variation in this measure during the interwar period reflects the effect of price level changes on the ad valorem equivalent of specific duties. In particular, the rapid inflation of World War I reduced tariff levels substantially from 1914 to 1920 while deflation of the early 1930s increased tariff levels substantially above the rates determined at 1930 prices. In addition, since the tariff rates in Figure 1 are value-weighted averages of individual tariff lines, they will be downward biased measures of the average tariff level in the SH schedule due to import substitution bias while also failing to reflect the distribution of tariff levels across items. These issues turn out to be central to our quantitative analysis because it is well recognized that both the mean and the dispersion of tariff rates play significant roles in determining the welfare effects of trade barriers. In particular, a high degree of dispersion in tariff rates across sectors can exacerbate the aggregate tariff distortion and worsen the allocation of resources across sectors.

\section{FIGURE 1 - UNITED STATES AD-VALOREM EQUIVALENT TARIFF RATE}

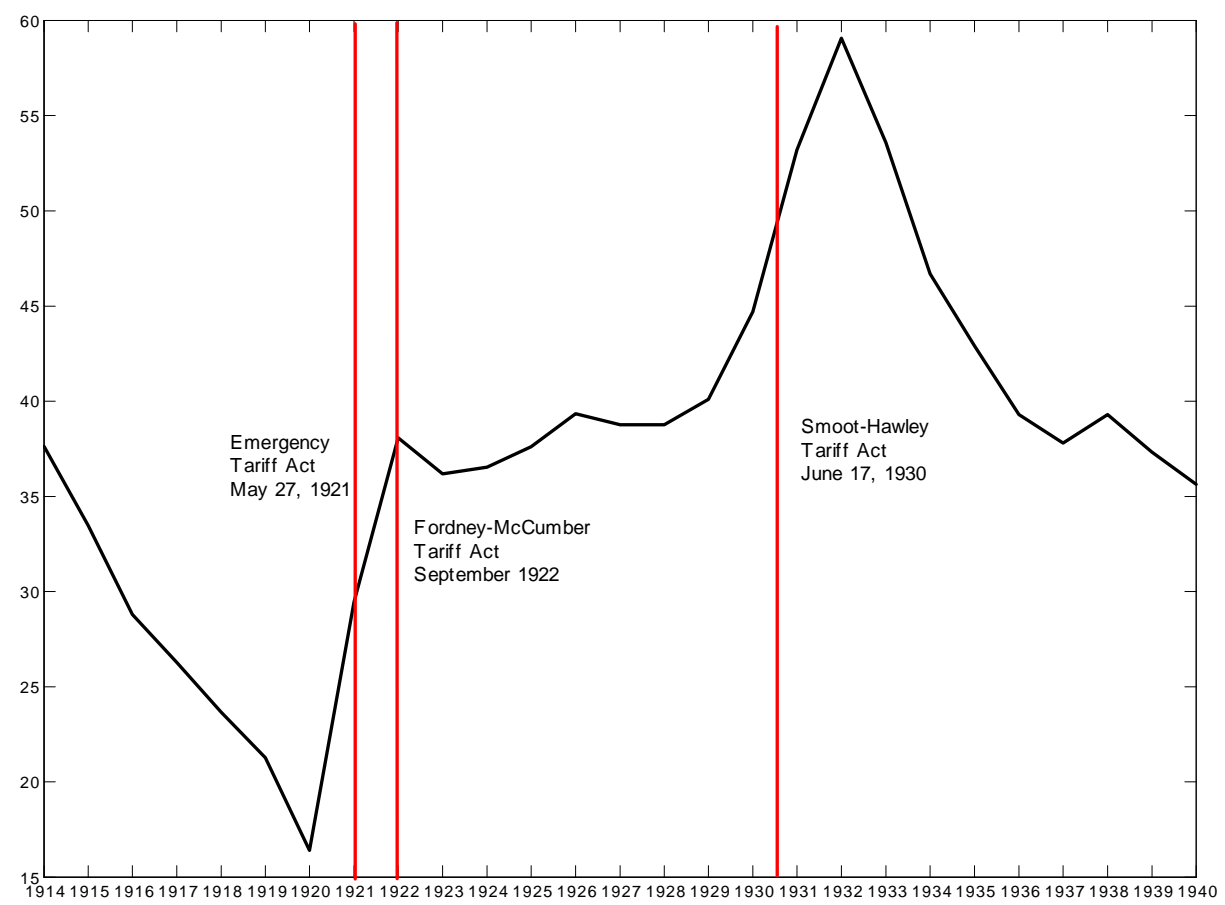

Notes: The ad-valorem equivalent rate is computed as the ratio of customs revenues to U.S. dutiable imports.

Our objective in this paper is to address the role of the dispersion of tariff rates under the SH legislation by developing a panel data set that traces the effective ad valorem tariff rates at the tariff line level over the period from 1930 to 1933. This panel can be used to address the question of how the distribution of effective tariff rates changed at the line item level as 
a result of the SH legislation and subsequent deflation. Combined with our structural model, it is possible to construct tariff wedges, which show the variation across sectors in the price of imported intermediates resulting from the changes in the tariff schedules. In particular, these wedges identify significant movements in both the mean and variance of tariff rates over time due to a combination of legislative changes and price-induced changes in the ad valorem equivalents of specific duties. ${ }^{3}$

We utilize these tariff wedges in a general equilibrium model to calculate the impact of changes in protection on macroeconomic variables, including employment, consumption, and domestic price indices. ${ }^{4}$ We derive two aggregate measures of the welfare impact of tariffs. The first is their effect on total factor productivity, which we define to be the number of units of the composite consumption bundle per unit of domestic productive resources. The second is the consumption equivalent, which is the compensation needed in units of aggregate consumption to make the representative agent indifferent between allocations under free trade and those under the existing tariff structure. In our benchmark parameterization, we find that the pre-Smoot Hawley tariff legislation had the effect of reducing total factor productivity relative to the free trade level by $1.2 \%$. The increases in tariffs associated with the Smoot Hawley and the deflation from 1930-33 had the effect of reducing TFP by an additional 0.5\%. We use a counterfactual exercise to show that if $\mathrm{SH}$ had not been passed, the effects of deflation would still have reduced TFP by $0.3 \%$ due to the widespread use of specific tariffs. The consumption equivalent measure yields effects of a similar magnitude for the benchmark parameterization. We also show the impact of the dispersion in the tariff structure across goods in the sense that the uniform tariff equivalent of the existing tariff schedule is substantially above the average tariff during this period.

Our paper contributes to the growing literature on the effect of policy distortions on aggregate outcomes. Restuccia and Rogerson (2008) use a calibration exercise to show that distortions in the allocation of capital and labor between firms can lead to substantial reductions in aggregate productivity. Hsieh and Klenow (2009) calculate the dispersion of marginal products of capital across firms in India and China, and argue that reducing the dispersion in these countries to the level observed in the US would have the effect of raising productivity by $40-60 \%$ in India and $30-50 \%$ in China. Our analysis abstracts from distortions in factor markets, and focuses on the effect of sectoral tariff wedges. The reduction in total factor productivity we find as a result of sectoral misallocations due to tariff protection are of a much smaller magnitude than those

\footnotetext{
${ }^{3}$ The potential importance of using microdata to address the pattern of protection was first shown by Crucini (1994), who constructed annual data from 1903 to 1940 on 32 imported items to examine the variability of effective ad valorem tariff rates. His data show that there is substantial variability in the ad valorem rates across sectors over time, resulting from both legislated tariff changes and differences in the importance of specific tariffs in the legislation applying to individual items. Our analysis extends Crucini's analysis by significantly expanding the range of products covered and by developing measures to evaluate how the distortions evolved over this period.

${ }^{4}$ Irwin (1998b) analyzes the effect of the Smoot Hawley tariffs using aggregate data and a CGE model to estimate sectoral effects, but does not utilize the degree of sectoral decomposition that we do.
} 
associated with factor market distortions, presumably due to the fact that trade accounted for a relatively small fraction of U.S. consumption and intermediate inputs during this period of history. We provide counterfactual exercises to illustrate the sensitivity of our results to changes in the import share of consumption goods and material inputs, as well as to the assumed elasticity of substitution between imports and domestic goods. These exercises provide some perspective on the potential for misallocation effects arising from commercial policy for other time periods and other nations.

We proceed in the following manner. Section 2 presents the multisector general equilibrium model and uses it to construct measures of the effects of tariff rates on aggregate variables. Sections 3 describes the construction of the panel data series on tariff rates, compares the sector level panel data to the line item data and presents estimates of sector level tariff wedges. Section 4 reports the results for the aggregate effects of tariff policy, and section 5 concludes.

\section{$2 \quad$ The Model}

Our goal in this section is to develop a tractable model that can be used in conjunction with our tariff line panel to obtain a measure of the impact of sectoral misallocation on aggregate variables. Our modeling choices are driven by two features of the data from this period. First, $75 \%$ of imports are intermediate goods according to the input-output tables for 1929 (Leontief (1941)). Therefore, we want a model that captures the substitution between imported materials and domestically produced materials in the production process. Second, there is substantial variation across tariff lines in the extent to which protection was increased during this period, as well as substantial differences across sectors in the degree to which imported inputs are used in the production process. For example, imports accounted for $75 \%$ of intermediate inputs in the sugar, glucose and starch industry, but less than $1 \%$ of intermediate inputs into the agricultural industry. This heterogeneity combined with the fact that sugar duties were much higher and varied more over time than most other agricultural duties indicates the different industry-level distortions of these respective duties. This motivates the use of a multisector model that allows for differential effects of tariff protection across the various production sectors.

\subsection{The Multisector Production Model}

We consider a GE production model with $N_{F}$ sectors producing non-traded final consumption goods and one sector representing exportable goods (sector 0 ). The $N_{F}$ final goods sectors correspond to the sectors in the Leontief input-output tables. This model allows us to capture substitution by firms between domestic and imported material inputs, as well substitution by consumers between domestic and imported final consumption goods. Our model also has a block recursive structure that provides simple measures of the effects of the tariff structure on aggregate variables. 
Each of the $N_{F}+1$ production sectors produce final output using inputs of domestic value added and material inputs. We assume that domestic capital and labor are used in the same proportions in all sectors, so that value added can be treated as a composite input whose price, $p_{V}$, is the same for all sectors. The technology for sector $j$ is given by the unit cost function $\left(a_{j V} p_{V}^{1-\sigma_{F}}+a_{j M} P_{j M}{ }^{1-\sigma_{F}}\right)^{\frac{1}{1-\sigma_{F}}}$. Here $P_{j M}$ is the price of material inputs in sector $j$, and $\sigma_{F}$ is the elasticity of substitution between value added and materials in the production of final goods. The material inputs for sector $j$ consist of domestic and imported materials. Assuming that the domestic material input is produced using value added alone and that the production of materials is perfectly competitive, the price paid for material inputs in sector $j$ will equal the unit cost of the composite material input, $P_{j M}=\left(a_{j d} p_{V}^{1-\sigma_{M}}+a_{j m} p_{j m}^{1-\sigma_{M}}\right)^{\frac{1}{1-\sigma_{M}}}$, where $p_{j m}$ is the cost of a composite of line item imported inputs used in production in sector $j$ and $\sigma_{M}$ is the elasticity of substitution between domestic and imported materials.

The sector-specific input prices are constructed from our tariff line panel using the inputoutput structure of the U.S. economy (Leontief (1941)) and the existing microeconomic tariff structure. Letting $\tau_{i}$ be one plus the ad valorem tariff rate on good $i$ and $q_{i}$ the world price of that good, the import price index for materials used by sector $j$ will be

$$
p_{j m}=\left[\sum_{i}^{N_{m}} b_{j i}\left(\tau_{i} q_{i}\right)^{1-\sigma_{m}}\right]^{\frac{1}{1-\sigma_{m}}} \quad j=0,1 . ., N_{F}
$$

where $N_{m}$ is the number of tariff lines, $\sigma_{m}$ is the elasticity of substitution between tariff lines, and the $b_{j i}$, are parameters that reflect the intensity with which good $i$ is used as an input into the production of sector $j .^{5}$

With perfect competition in the production of materials and final goods, the price of a final good will equal its unit cost,

$$
p_{j F}=\left(a_{j V} p_{V}^{1-\sigma_{F}}+a_{j M}\left(a_{j d} p_{V}^{1-\sigma_{M}}+a_{j m} p_{j m}^{1-\sigma_{M}}\right)^{\frac{1-\sigma_{F}}{1-\sigma_{M}}}\right)^{\frac{1}{1-\sigma_{F}}}, j=0,1 . ., N_{F}
$$

We assume that the exportable good is sold on world markets at an exogenously given world price, $q_{0 F} \equiv 1$. The zero profit condition for the exportable sector can be inverted to solve for the return to domestic value added as a function of the price of imported goods used in the exportable sector, $p_{V}^{*}\left(p_{0 m}\right)$. This solution can then be inserted into the remaining zero profit conditions to solve for the prices of the $N_{F}$ non-traded consumption goods. We thus have solutions for prices of domestic non-traded goods and factor inputs as a function of the vector of tariffs, $\boldsymbol{\tau}$, and world prices of the home country importables, $\mathbf{q}$, that determine the $p_{j m}$ from

\footnotetext{
${ }^{5}$ The $b_{i j}$ are functions of both the input-output structure of the US economy in 1929 and a base period price vector. The details of the mapping between the two are discussed in section 3.2.
} 
(1). ${ }^{6}$

In the case of a small open economy, $\mathbf{q}$ is exogenously given and there will be complete pass through of tariffs to prices paid by the domestic purchasers of imports. We will treat the US as a small open economy in our analysis below, which merits some discussion. Our assumption ensures that all of the distorting effects of the tariff are borne by the US, and thus can be thought of as representing an upper bound on the aggregate productivity effects of trade barriers. $^{7}$ In contrast, if US tariff increases have the effect of reducing world prices, this will represent a terms of trade improvement for the US that will be an offset against the productivity losses that we calculate. This could be captured in our analysis by allowing for incomplete passthrough of tariffs to domestic prices. However, there is little evidence of negative effects of tariff rate changes on world prices in our tariff line data. ${ }^{8}$ The absence of a significant correlation seems consistent with the fact that US imports were only $\$ 4.4$ billion in 1929 , which represented approximately $12 \%$ of world trade. Also, tariff retaliation by foreign countries would have the effect of mitigating the terms of trade improvements that the US experienced on account of its own tariff rate increases.

We conclude our discussion of the production side of the model with the production function for domestic value added,

$$
V=A K^{1-\beta} L^{\beta}
$$

where $K$ is the input of capital, $L$ is the input of labor, and $A$ is the productivity level. We will undertake a short run analysis in which the capital stock is assumed to be fixed. The market wage will be determined by the marginal productivity condition,

$$
\frac{w}{p_{V}}=A \beta\left(\frac{K}{L}\right)^{1-\beta}
$$

For a given $K / L$, protection will lower the wage rate because it lowers $p_{V}=p_{V}^{*}\left(p_{0 m}\right)$. The level of labor input will be determined as part of the household decision problem, to which we now turn.

\footnotetext{
${ }^{6}$ Our assumption of a single export sector is made to be consistent with our assumptions of a single (composite) domestic factor input and exogenously given world prices. The latter assumptions ensure that national income can be maximized by specializing in the traded good that yields the highest return to the domestic factor of production.

${ }^{7}$ We should note however that the effects could be larger in a dynamic model, where tariffs affect capital accumulation.

${ }^{8}$ If US tariffs have a significant effect on world prices, then the world price of goods on which the US imposes higher tariffs should fall relative to other goods. To test this, we regressed changes in world prices on changes in tariff rates, allowing for differential coefficients based on whether goods had ad valorem or specific tariffs. We did not find a significant negative effect of tariff changes on prices for either type of protection.
} 


\subsection{Household Decisions and Market Equilibrium}

The preferences of households are assumed to take the following form:

$$
\begin{aligned}
U & =\frac{C^{1-s}}{1-s}-\frac{\nu L^{\gamma}}{\gamma} \\
\text { where } C & =\left(\sum_{j=1}^{N_{F}} a_{c j}^{\frac{1}{\sigma_{C}}} C_{j}^{\frac{\sigma_{C}-1}{\sigma_{C}}}+a_{c m}^{\frac{1}{\sigma_{C}}} C_{m} \frac{\frac{\sigma_{C}-1}{\sigma_{C}}}{\sigma^{\frac{\sigma_{C}}{\sigma_{C}-1}}}\right.
\end{aligned}
$$

The intertemporal elasticity of substitution in consumption is given by $\frac{1}{s}$, and the Frisch elasticity of labor supply by $\frac{1}{\gamma-1}$. The consumption levels $C_{j}$ are demands for the final goods from the production sectors $j=1, . ., N_{F}, C_{m}$ is the consumption of imports, and $\sigma_{C}$ is the elasticity of substitution between all consumption goods, domestic and imported.

The household budget constraint is $\sum_{j=1}^{N_{F}} p_{j F} C_{j}+p_{c m} C_{m}=w L+r K+T$, where $T$ is the amount of tariff revenue transferred to households. The prices $p_{c m}$ and $p_{j F}$ are the indices for imported consumption goods and each non-traded final good $j$, constructed as in equations (1) and (2), respectively. The household consumption allocation between domestic and imported goods can be solved using two stage budgeting. The necessary conditions for choice of $C$ and $L$ yield

$$
\begin{aligned}
C^{s} L^{\gamma-1} & =\frac{w}{\nu P_{C}} \\
\text { where } P_{C} & =\left(\sum_{j=1}^{N_{F}} a_{c j} p_{j F}^{1-\sigma_{C}}+a_{c m} p_{c m}^{1-\sigma_{C}}\right)^{\frac{1}{1-\sigma_{C}}}
\end{aligned}
$$

$P_{C}$ is the price index for consumption, which can be used to derive the shares of expenditure on domestic and imported goods in aggregate consumption,

$$
\begin{aligned}
\mu_{j}\left(\frac{p_{j F}}{P_{C}}\right) & =a_{c j}\left(\frac{p_{j F}}{P_{C}}\right)^{1-\sigma_{C}} \quad j=1, \ldots, N_{F} \\
\mu_{m}\left(\frac{p_{c m}}{P_{C}}\right) & =a_{c m}\left(\frac{p_{c m}}{P_{C}}\right)^{1-\sigma_{C}} .
\end{aligned}
$$

Letting $Y_{j F}$ denote the output of the final good of sector $j$, the market clearing conditions for domestic consumption goods are

$$
p_{j F} Y_{j F}=\mu_{j}\left(\frac{p_{j F}}{P_{C}}\right) P_{C} C \quad j=1, . ., N_{F} .
$$

The market clearing condition for domestic value added requires that the sum of demands for value added across sectors equal the supply, $\sum_{j=0}^{N_{F}} \theta_{j V} p_{j F} Y_{j F}=p_{V} V$, where $\theta_{j V}\left(p_{V}, p_{j m}\right)=$ 
$\left(\frac{\partial P_{j F}\left(p_{V}, p_{m j}\right)}{\partial p_{V}}\right)\left(\frac{p_{V}}{p_{j F}}\right)$ is the share of value added (both direct and as a share of materials) in sector $j$. This market clearing expression can be used to solve for the level of exports as a function of aggregate value added and the output of non-traded goods,

$$
Y_{0 F}=\frac{p_{V} V-\sum_{j=1}^{N f} \theta_{j V} \mu_{j} P_{C} C}{\theta_{0 V}}
$$

In order to determine the level of tariff revenue, we need to derive demands for the imported products at the tariff line level. The share of imports of tariff line $i$ in the expenditure of activity $j$ on imported inputs is given by $\alpha_{j i}\left(\frac{q_{i} \tau_{i}}{p_{j m}}\right)=\frac{\partial p_{j m}}{\partial\left(q_{i} \tau_{i}\right)} \frac{q_{i} \tau_{i}}{p_{j m}}=b_{j i}\left(\frac{q_{i} \tau_{i}}{p_{j m}}\right)^{1-\sigma_{m}}$. Using (7), the value of imports in tariff line $i$ will be the sum of the value of imports for final consumption, $\alpha_{c i} \mu_{m} P_{C} C$, and the value of imports for intermediate use from the various production activities, $\sum_{j=0}^{N_{F}} \alpha_{j i} \theta_{j m} p_{j F} Y_{j F}$, where $\theta_{j m}=1-\theta_{j V}$ is the share of imported materials in the cost of production of good $j$. Using (8) and (9), we obtain an expression for tariff revenue as a function of value added and aggregate consumption:

$$
\begin{aligned}
T & =\Gamma_{V} p_{V} V+\Gamma_{C} P_{C} C \\
\text { where } \Gamma_{V} & =\sum_{i=1}^{N_{m}}\left(\frac{\tau_{i}-1}{\tau_{i}}\right) \alpha_{0 i}\left(\frac{\theta_{0 m}}{\theta_{0 V}}\right)>0 \\
\Gamma_{C} & =\sum_{i=1}^{N_{m}}\left(\frac{\tau_{i}-1}{\tau_{i}}\right)\left(\sum_{j=1}^{N_{F}}\left(\alpha_{j i} \theta_{j m}-\frac{\alpha_{0 i} \theta_{0 m} \theta_{j V}}{\theta_{0 V}}\right) \mu_{j}+\alpha_{c i} \mu_{m}\right) .
\end{aligned}
$$

The terms $\Gamma_{V}$ and $\Gamma_{C}$ capture the effect of an increase in value added and consumption on tariff revenue. These factors play a key role in measuring the distortions from the tariff structure, because they represent the fiscal effects of household decisions regarding labor supply and consumption.

To interpret the coefficient $\Gamma_{V}$, note that an increase in value added will result in an increase in production of exportable goods from (9). This increase in exports requires an increase in the import of intermediate inputs for the exportable sector, which raises tariff revenue and has a positive spillover to household income. The interpretation of $\Gamma_{C}$ is more complicated, because it involves a reallocation of resources between the traded and non-traded goods sectors. An increase in aggregate consumption will raise imports of final consumption goods and imports of materials to produce the non-traded domestic consumption goods. However, it will also result in a reduction in production of exportables, and thus a reduction in imported material inputs to the exportable sector. This leads to an ambiguous effect of an increase in aggregate consumption on tariff revenue, since tariff revenue could actually fall if exports are intensive in the use of intermediate inputs relative to other production and consumption activities. 
Substituting (10) into the budget constraint yields

$$
\frac{C}{V}=T F P(\boldsymbol{\tau}, \mathbf{q})=\frac{p_{V}\left(1+\Gamma_{V}\right)}{P_{C}\left(1-\Gamma_{C}\right)}
$$

The right hand side of (11) expresses the amount of the composite consumption good that can be generated per unit of the composite factor input as a function of the tariff structure and the terms of trade. This index can be interpreted as a measure of total factor productivity for the open economy. The numerator is the social return to value added, which is the market return plus the additional tariff revenue generated from an additional unit of value added. The denominator of this expression is the social cost of consumption, which is the market cost less the tariff revenue generated by additional imports (which could be negative). The introduction of tariffs will reduce the real return to value added, $\frac{p_{V}}{P_{C}}$, relative to the free trade level because protection reduces the return to value added in the exportable sector and raises the relative cost of imported intermediates and final goods used in the consumption bundle. The adjustment for tariff revenue, $\frac{\left(1+\Gamma_{V}\right)}{\left(1-\Gamma_{C}\right)}$, will be equal to unity at free trade and at autarky from (10). It can be shown that this measure of total factor productivity is maximized at free trade in the small country case, since tariffs result in deadweight losses by causing inefficient substitution of domestic goods for imports.

In addition to its impact on the efficiency of resource use, protection will also distort labor supply and consumption decisions. Substituting (6) into (11) and using the fact that $w L=$ $\beta p_{V} V$, we obtain a solution for the equilibrium level of employment

$$
L(\boldsymbol{\tau}, \mathbf{q})=\left(\frac{\beta}{\nu} \frac{p_{V}}{P_{C}}\left(A K^{1-\beta}\right)^{1-s}(T F P)^{-s}\right)^{\frac{1}{\beta(s-1)+\gamma}}
$$

where $\beta(s-1)+\gamma>0$ for all $s \geq 0$ since $\gamma \geq 1$. The existence of tariff protection will reduce both $\frac{p_{V}}{P_{C}}$ and TFP relative to the free trade level. The former effect will tend to reduce the level of employment relative to free trade, whereas the latter effect will tend to increase it. Thus, tariff protection will have an ambiguous effect on employment relative to the free trade level. The equilibrium level of consumption is obtained by substituting from (12) and (4) into (6), which yields

$$
C(\boldsymbol{\tau}, \mathbf{q})=\left(\left(\frac{\beta}{\nu} \frac{p_{V}}{P_{C}}\right)^{\beta}\left(A K^{1-\beta}\right)^{\gamma}(T F P)^{\gamma-\beta}\right)^{\frac{1}{\beta(s-1)+\gamma}}
$$

Consumption will be increasing in $\frac{p_{V}}{P_{C}}$ and $T F P$, so tariff protection will unambiguously reduce consumption relative to the free trade level.

The solutions to (13) and (12) can be substituted into (5) to construct the indirect utility 
function

$$
W(\boldsymbol{\tau}, \mathbf{q})=\frac{C(\boldsymbol{\tau}, \mathbf{q})^{1-s}}{1-s}-\frac{\nu L(\boldsymbol{\tau}, \mathbf{q})^{\gamma}}{\gamma}
$$

(14) will be maximized at free trade in the small country case. To calculate the effect of a given tariff structure, $\boldsymbol{\tau}_{0}$, on welfare we can calculate the level of consumption that would lead to the same welfare as at free trade, given the distorted labor supply. This consumption equivalent value, which we denote $C^{E}$, is the solution to

$$
U\left(C^{E}, L\left(\boldsymbol{\tau}_{0}, \mathbf{q}\right)\right)=W(1, \mathbf{q})
$$

The expressions (11) and (15) can be used to measure the aggregate effects of tariff protection on resource allocation and welfare. If the tariff structure does not affect aggregate employment, then aggregate value added will be constant and the loss in consumption due to tariff protection will coincide with the reduction in TFP. When tariff protection reduces (raises) employment, the loss in consumption will be smaller (larger) than the reduction in TFP.

A second question of interest is the effect of the variance in the tariff structure on welfare. This question can be addressed by solving for the uniform tariff that yields the same welfare level as the existing tariff structure. Letting $\boldsymbol{\tau}_{0}$ be an initial tariff vector and $\mathbf{q}_{0}$ the vector of world prices of importable goods, the uniform tariff vector $\tau^{U}$ that yields the same domestic welfare will be the solution to

$$
W\left(\boldsymbol{\tau}^{U}, \mathbf{q}_{0}\right)=W\left(\boldsymbol{\tau}_{0}, \mathbf{q}_{0}\right)
$$

This measure corresponds to the trade restrictiveness index (TRI) constructed by Anderson and Neary (2005).

\section{The Tariff Line Data and Sectoral Price Indices}

Three volumes of the FTNUS have been painstakingly converted from the original text source to an electronic data archive in order to construct a panel consisting of three cross sections. The first cross section records imports during the first six months of 1930 when the FordneyMcCumber tariffs of 1922 were still in effect, which we will refer to as the 1930A cross section. The 1930B cross section covers the last six months of 1930 when the Smoot-Hawley tariffs were first applied to U.S. imports. The third cross section covers the entire year 1933. We chose two post Smoot Hawley cross sections to illustrate how the tariff structure changed as a result of the effect of price deflation on sectors with specific tariffs. The year 1933 was chosen for the second post SH cross section for two reasons. First, it is the trough of the U.S. business cycle and captures the maximum change in imports resulting from the collapse in aggregate demand over the business cycle contraction phase. Second, 1933 also coincides with the price level trough. This is important for our study of the relationship between imports and tariffs 
because many customs duties were specific. Thus, the price level trough also coincides with the peak ad-valorem-equivalent rates of duty for many imported goods. As far as we know, this is the only archive of U.S. imports and duties in existence at the line item level for the 1930s.

Table 1 provides a sense of the scope of our cross sections. The number of line items from the original FTNUS source document increases from 4,861 to 5,280 and then to 5,629 as we move across the three cross sections. The larger increase in 1930, despite the shorter time interval, is largely due to the expansion of the scope and level of detail in the tariff schedules themselves. Relative to these maximums, the fraction of available data varies across the measures of value imported, quantity imported, import price, duty collected and the ad-valorem-equivalent tariff rate. The value imported is available for more than $95 \%$ of the line items. The quantity data are next most abundant, available for about $90 \%$ of the line items. The price data are imputed as unit values, taking the ratio of value imported to the physical quantity imported and thus require availability of both measures. As such, they are available for fewer line items than either value or quantity, $85 \%$ typically. Since some items are duty free, the duty and tariff columns also have fewer entries than the value column. In sum, the cross-sections represent the complete record of U.S. trade flows at the line-item basis.

TABLE 1: SCOPE OF THE CROSS-SECTIONS (SOURCE DATA)

\begin{tabular}{lccccccc}
\hline \hline & \multicolumn{2}{c}{ Number of observations } & & \multicolumn{3}{c}{ Proportion available } \\
\cline { 2 - 3 } \cline { 7 - 8 } & Pre-SH & Post-SH & 1933 & & Pre-SH & Post-SH & 1933 \\
\hline Tariff lines & 4,861 & 5,280 & 5,629 & & 1.00 & 1.00 & 1.00 \\
Value imported & 4,750 & 5,001 & 5,302 & & 0.98 & 0.95 & 0.94 \\
Quantity imported & 4,388 & 4,685 & 5,007 & & 0.90 & 0.89 & 0.88 \\
Price & 4,290 & 4,422 & 4,690 & & 0.88 & 0.84 & 0.83 \\
Duty & 4,018 & 4,321 & 4,487 & & 0.83 & 0.82 & 0.80 \\
Ad-valorem rate & 3,980 & 4,207 & 4,345 & & 0.82 & 0.80 & 0.77 \\
\hline
\end{tabular}

\subsection{Construction of Panel Data}

Conducting research in an environment with enormous heterogeneity in the products and the tariff levels across them poses some unique challenges. To measure the change in the quantity imported in response to a good-specific tariff change requires careful control of the quality of the matches of goods across time. Attention must also be paid to the fact that tariff lines are sometimes split or combined. This makes some rudimentary aggregation necessary to avoid excluding a significant number of entry-level items.

To match goods across time, we employed a text-matching algorithm to tariff lines in 1930A with those in the 1930B and 1933 cross sections. Since there was both splitting and aggregation of tariff lines during the period, the text matching algorithm did not provide one to one matches 
in many cases. In these cases, we constructed an aggregated line item series by taking a weighted average of the individual line items using the 1930A import values as weights. This procedure resulted in a balanced panel of 495 line items, accounting for $18 \%$ of trade in $1930 \mathrm{~A}$ and $25 \%$ of trade in 1933. The reduction in the number of tariff lines occurs for two reasons. First, aggregation naturally reduces the number of individual tariff lines and due to a large degree of re-organization between $1930 \mathrm{~A}$ and 1930B/1933; it is common for two or more line items to be matched to the same line item in a later cross-section. Second, aggregation exacerbates missing data issues. Any set of line items which is matched to any individual observation with missing data have to be discarded since the aggregation cannot be performed. ${ }^{9}$

Let $\tilde{\tau}_{i t}$ denote one plus the legislated ad valorem tariff for tariff line $i$ and let $w_{i t}$ denote the legislated specific tariff in the tariff schedule implemented at time $s$. The effective ad valorem tariff rate at time $t$ is thus defined as

$$
\tau_{i t}\left(q_{i t}\right)=\tilde{\tau}_{i s}+\frac{w_{i s}}{q_{i t}}
$$

where $q_{i t}$ is the world price of good $i$ at time $t$. The tariff rates under the Fordney-McCumber Act were in effect for the first 6 months of 1930, which is denoted as $t=0$ (the 1930A cross section). The Smoot Hawley tariffs schedule was in effect for the $1930 \mathrm{~B}(t=1)$ and $1933(t=2)$ cross sections. The variation in effective tariff rates between $t=1$ and $t=2$ will thus include only the price level induced changes resulting from changes in import prices. ${ }^{10}$. We will also use (16) to construct the tariff vector $\tau_{0}\left(q_{t}\right)$ for $t=1,2$ which represents the counterfactual effective rates that would have been observed if the Smoot Hawley legislation had not been passed.

We can provide a sense of how representative our balanced panel is of the underlying crosssections by comparing their distributions and reporting key statistics. Arguably one of the most important distributions is the microeconomic distribution of ad-valorem-equivalent tariff levels across goods. Figure 2 plots kernel estimates of the distributions of tariffs before Smoot-Hawley was passed, after Smoot-Hawley was passed and in 1933. The solid line is the raw (source) microdata and the dashed line is the balanced panel data. It is quite evident that the balanced panel is representative of the underlying line-item tariff data. The tariff levels are underestimated by the panel, but the differences are quite minor, the largest difference being the pre-Smoot Hawley panel where the median ad-valorem-equivalent rate is 0.31 compared to 0.37 in the full archive. Table A1 of the appendix reports additional comparisons of the full cross-section and panel.

\footnotetext{
${ }^{9} \mathrm{~A}$ detailed discussion of the quality of the matches from the text matching algorithm, as well as further discussion of the aggregation procedure, is provided in Appendix A.

${ }^{10}$ The significant role played by price level changes in the effective tariff rate has been emphasized by Crucini (1994) and Irwin (1998). The effective tariff rate in (16) can be decomposed into a policy component, which evaluates the change due to legislated changes in $\tilde{\tau}$ and $w$ at given world prices, and a price level effect. The correlation between the policy effects and price effects is -.049.
} 


\section{FIGURE 2 - TARIFF COMPARISONS, ORIGINAL ARCHIVE AND PANEL}
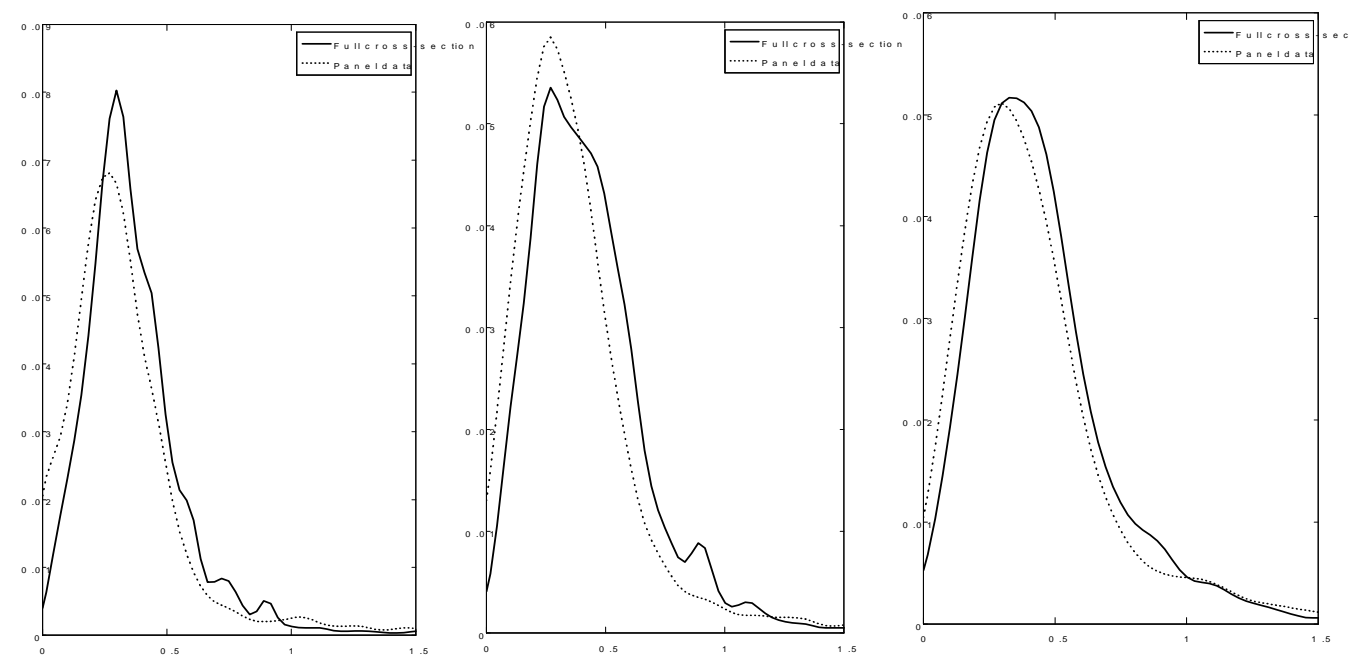

Note: Solid line is density estimate of original tariffs $(\tau-1)$ in the FTNUS archive, dashed line is panel data.

A second concern about the reliability of our panel data is the extent to which we have successfully matched industries over time. An important issue in our analysis is the extent to which tariffs vary over time, whether due to changes in trade policy or due to changes in import prices that alter the protective effect of ad valorem tariffs. If we are not matching industries correctly over time, this will introduce a measurement error into our comparisons of tariff rates over time. Since the tariff legislation did not change between the 1930B and 1933 samples, a crude measure of the quality of a match is the difference between the tariff rate (whether ad valorem or specific) for $1930 \mathrm{~B}$ and 1933 . For ad valorem tariff rates, $75 \%$ are within $1 \%$ of the base period rate, $77 \%$ are within $5 \%$ of the base period rate, and $91 \%$ are within $25 \%$ of the base period rate. The average base period (1930B) tariff rate was 16 percent. For specific tariff rates, $81 \%$ are within $1 \%$ of the base period duty, $84 \%$ are within $5 \%$ of the base period duty, and $89 \%$ are within $25 \%$ of the base period duty. The average base period (1930B) specific duty was 25 cents.

\subsection{Construction of Sectoral Price Indices}

The import price indices defined in (1) represent ideal price indices for the cost of imports to the $N_{F}+1$ production sectors and final consumption. Our tariff line panel provides the values 
of $\tau_{j t}$ and $q_{j t}$ required for construction of these indices, but we also need to obtain values for the taste parameters, $b_{j i}$, and the elasticities of substitution, $\sigma_{m}$.

The expression for the share of imports from tariff line $i$ by activity $j, \alpha_{j i}\left(\frac{q_{i} \tau_{i}}{p_{j m}}\right)=b_{j i}\left(\frac{q_{i} \tau_{i}}{p_{j m}}\right)^{1-\sigma_{m}}$, can be used to express the $b_{i j}$ in terms of observables at time $t$ and the elasticity of substitution,

$$
b_{j i}=\alpha_{j i t}\left(\frac{q_{i t} \tau_{i t}}{p_{j m}\left(\mathbf{p}_{t}\right)}\right)^{\sigma_{m}-1}
$$

Note that since the $\alpha_{i j t}$ are homogeneous of degree 0 in the vector of coefficients $b_{i}$, the system of equations (17) determines the $b_{i j}$ vector only up to a multiplicative constant. We can determine unique values for a given value of $\sigma_{m}$ by choosing a normalization of base period price such as $p_{i m 0}\left(\mathbf{p}_{0}\right)=1$

The tariff line data provide the total value of imports in the tariff line $i, v_{i t}$, but not the allocation of these imports across the final goods sectors as required for the $\alpha_{j i t}$. However, we are able to construct a proxy for the budget shares in the base year, $\alpha_{i j 0}$, using the Leontief tables and the tariff line data by making two assumptions. The first assumption is that final good industry $i$ 's share of consumption of imports from tariff lines associated with final goods sector $k$ is equal to its share of consumption of domestically produced intermediates from final goods sector $k$. Letting $v_{i j 0}$ denote imports by industry $i$ in tariff line $j$ in the base year, $J_{k}$ denote the index set of tariff lines associated with industry $k$, and $\beta_{k i}$ the share of industry $k$ 's output that is sold as intermediate goods to sector $i$, this assumption implies that $\sum_{j \in J_{k}} v_{i j 0}=\beta_{k i} \sum_{j \in J_{k}} v_{j 0}$. The second assumption is that the imports of final goods sector $i$ from final goods sector $j$ are allocated across tariff lines in proportion to their share in total imports from industry $k$, which requires $\frac{v_{i j}}{\sum_{j \in J_{K}} v_{i j}}=\left(\frac{v_{j}}{\sum_{j \in J_{K}} v_{j}}\right)$. Together these assumptions imply that $v_{i j}=\beta_{k i} v_{j}$ for all $j \in J_{k}$, so that the base year budget shares can be expressed as

$$
\alpha_{i j 0}=\frac{v_{i j 0}}{\sum_{j} v_{i j 0}}=\frac{\beta_{k i} v_{j 0}}{\sum_{k} \sum_{j \in J_{k}} \beta_{k i} v_{j 0}} \quad i=1, . ., N_{C} ; j=1, . ., N_{m} .
$$

The base year budget shares are calculated using Leontief's 1929 input-output tables for the $\beta_{k i}$ and the 1930 (pre HS) tariff line data for the $v_{j 0}$.

To complete the construction of the import price indices, we calibrate the values of $\sigma_{m}$ and $\sigma_{C}$ to match the change in imports between 1930A and 1930B in response to the changes in tariffs and world prices. Using (1) and (8) we can express the demand for imports as materials by sector $j$ from tariff line $i$ as $m_{j i}=\alpha_{j i}\left(\frac{q_{i} \tau_{i}}{p_{j m}}\right) \theta_{j m}\left(p_{V}, p_{j m}\right) \mu_{j}\left(\frac{p_{j F}}{P_{C}}\right) P_{C} C$. Totally differentiating this expression and defining $\hat{x}=\frac{d x}{x}$, we have

$$
\hat{m}_{j i}=-s_{j i}^{\tau}\left(\hat{\tau}_{i}+\hat{q}_{i}\right)+s_{j i}^{V} \hat{p}_{V}+s_{j i}^{F} \hat{P}_{i F}+s_{j i}^{V} \hat{P}_{C}+\hat{C}
$$


where the coefficients $s_{j i}^{k}$ are functions of the elasticities of substitution, $\left(\sigma_{C}, \sigma_{F}, \sigma_{M}, \sigma_{m}\right)$, and the cost shares. A similar expression can be derived for $\hat{m}_{c i}$, and the model's prediction of the change in imports from tariff line $i, \hat{m}_{i}$, will be an import share weighted sum of the $\hat{m}_{j i}$. Assuming that $\sigma_{F}=1, \sigma_{m}=\sigma_{M}$, and that $\hat{p}_{V}=\hat{p}_{j F}=\hat{p}_{C}=\hat{w}$ are given by the rate of change in the GDP deflator, we obtain an expression for the change in imports in tariff line $i$ as a function of $\sigma_{C}$ and $\sigma_{m}$. We choose the values $\sigma_{C}$ and $\sigma_{m}$ to match price and quantity movements in the data between the 1930A and 1930B cross sections. We then compare the change in imports between the 1930A and 1933 cross sections with the predictions based on our calibrated parameters as an out-of-sample check on our parameter choices. The results for the 1930B and 1933 cross-sections are displayed in the two panels of Figure 3.

\section{FIGURE 3 - ACTUAL AND PREDICTED INDUSTRY-LEVEL CHANGES}
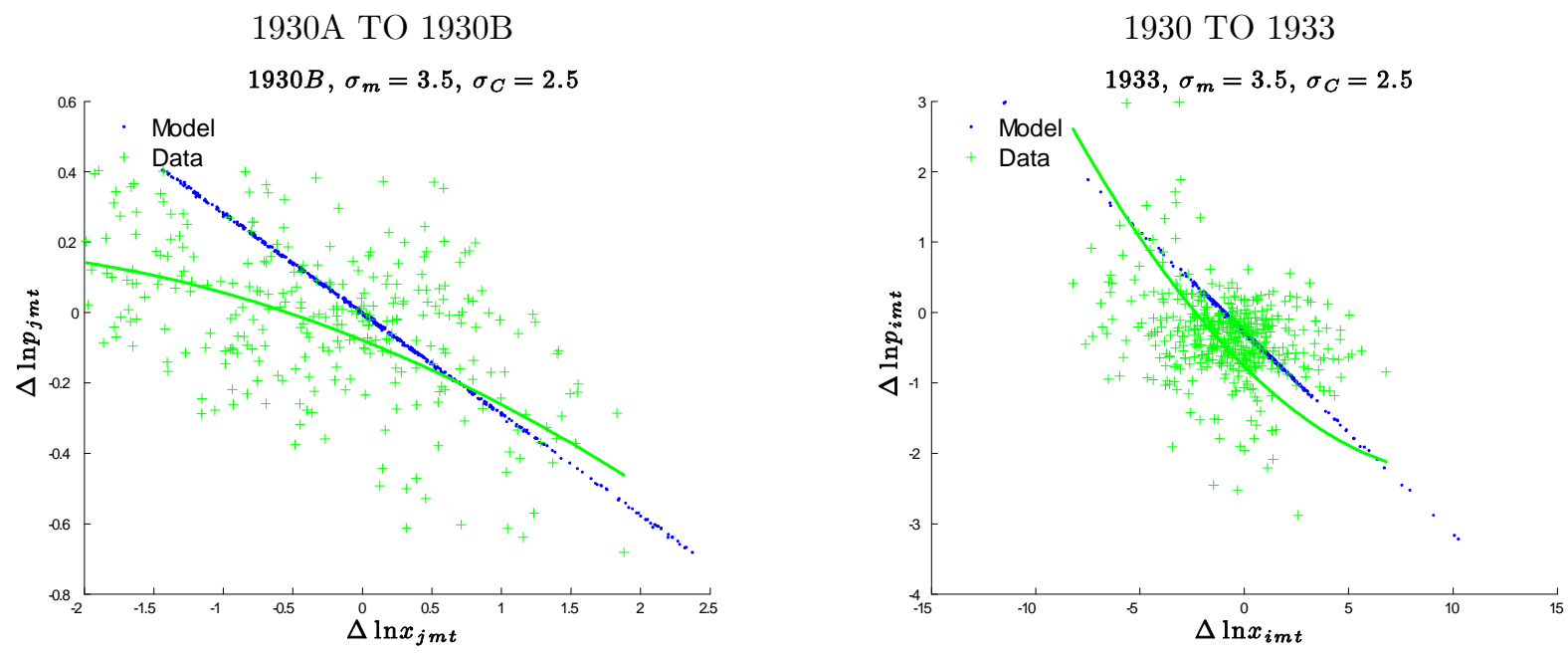

Figure 3 displays the model predicted data (blue dots), the actual data (green crosses) and a quadratic regression of actual import prices changes on import quantity changes. We observe that the relationship between import price and quantity changes in 1933 is nearly linear. Further, setting $\sigma_{m}=3.5$ and $\sigma_{C}=2.5$, we find that the model matches the data very closely. In 1930 we observe a less linear relationship between prices and quantities. In particular, there are a number of goods for which we observe large declines in import quantities in response to moderate import price increases. This is arguably reasonable if the legislated tariff increases were foreseen by importers, who were in turn able to increase imports in the first half of 1930 before the tariff changes took effect. Nonetheless, overall the model matches the data relatively well. ${ }^{11}$

\footnotetext{
${ }^{11}$ These parameter values yield a price elasticity of import demand elasticity that averages 3.1 Our estimates of the elasticity parameters are relatively low compared to those presented elsewhere in the trade literature. For instance, Eaton and Kortum suggest an elasticity of substitution across imports near 8, while Simonovka and Waugh (2011) suggest that an improved estimate would be closer to 4 . We note that increasing $\sigma_{m}$ from our benchmark estimate results in higher tariff wedges a larger role for tariff policy in determining trade flows. In light of our relatively conservative elasticity estimate, we also consider a counterfactual exercise with larger elasticities.
} 
Given our benchmark parameterization, we can use our constructed import price indices to measure the impact of the SH policy on the cost of imported goods across industries and over time. Specifically, we calculate the tariff wedges for each industry in year $t$ to be

$$
\frac{p_{j m}\left(\mathbf{p}_{t}\right)}{p_{j m}\left(\mathbf{q}_{t}\right)}=\left[\frac{\sum_{i}^{N_{m}} \alpha_{j i 0}\left(\frac{q_{i t} \tau_{i t}}{q_{i 0} \tau_{i 0}}\right)^{1-\sigma_{m}}}{\sum_{i}^{N_{m}} \alpha_{j i 0}\left(\frac{q_{i t}}{q_{i 0} \tau_{i 0}}\right)^{1-\sigma_{m}}}\right]^{\frac{1}{1-\sigma_{m}}} \quad i=0, . ., N_{F} \text { and } C
$$

given the individual tariff line item data, the Leontief share data and our parameterization of $\sigma_{m}$. The results are presented in Figure 4 where we have sorted the tariff wedges from lowest to highest based the 1930A, pre-SH tariff wedge.

\section{FIGURE 4 - ESTIMATED TARIFF WEDGES BY INDUSTRY AND CROSS-SECTION}

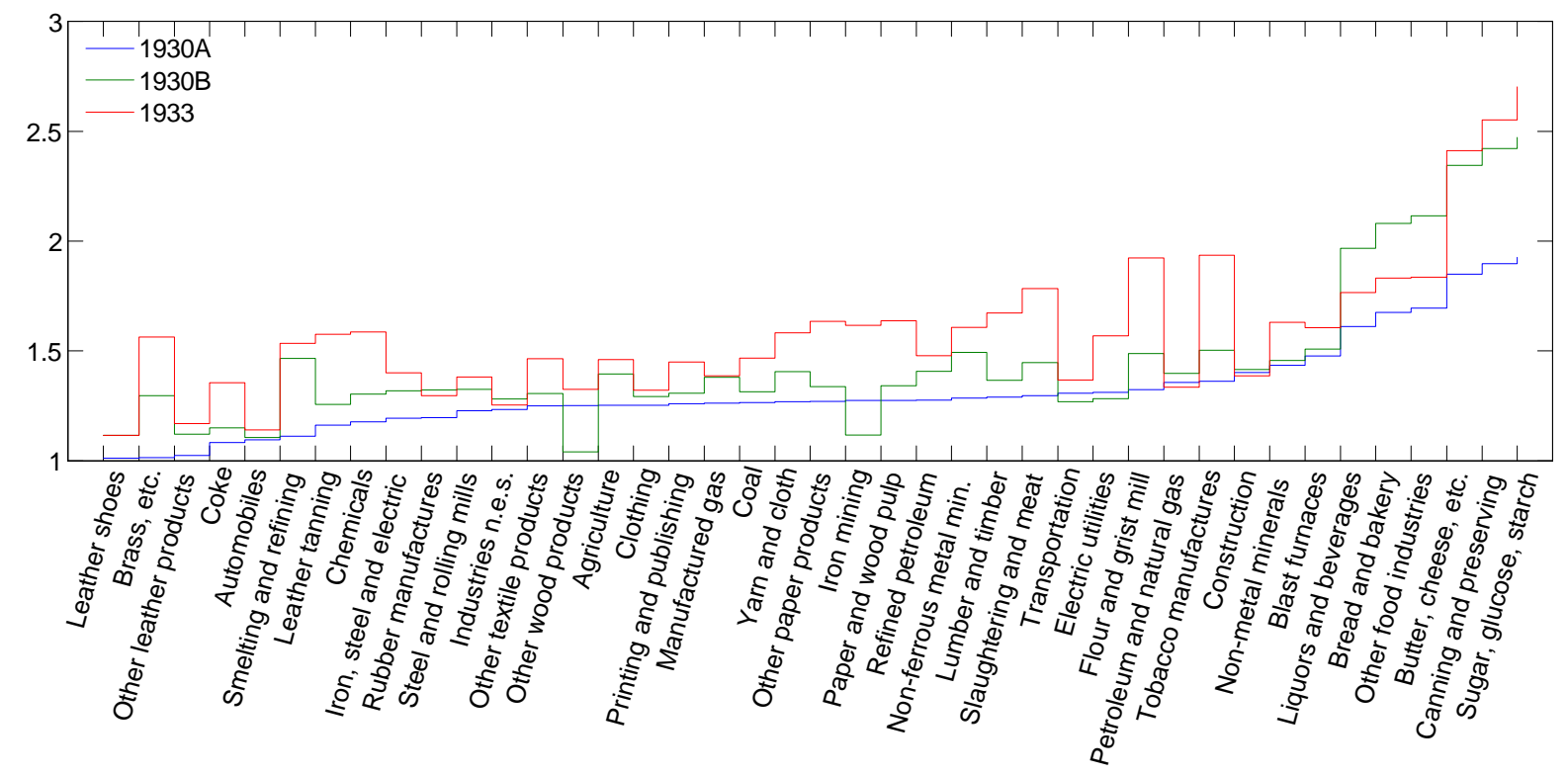

Figure 4 demonstrates a striking degree of heterogeneity in the tariff wedge across industries in all three cross-sections. Even before the SH policy was implemented (the blue line) we observe that tariff wedge ranges from a low of 1.01 (leather shoes) to a high of 1.91 (sugar, glucose, and starch). Over time we observe that the heterogeneity increases with the onset of the SH tariff policy and the propagation of the Great Depression. The green line in Figure 4 represents the tariff wedges in 1930 after the SH-policy has been passed. As expected, trade barriers rose for most industries, with many of the largest increases occurring in industries that already had large tariff wedges before the change in policy. By 1933 the wedges range from a low of 1.11 (leather shoes) to a high of 2.73 (sugar, glucose and starch). These are enormous increases in trade barriers. At the low end, the leather shoe industry experiences a 10 percent increase from the 
pre-SH period, which is not small by historical standards). However, it seems minute relative to the 82 percent increase the sugar, glucose and starch industry over the same time.

TABLE 2 - TARIFF WEDGE MOMENTS

\begin{tabular}{lccc}
\hline \hline & $1930 \mathrm{~A}$ & $1930 \mathrm{~B}$ & 1933 \\
\hline Mean & 1.32 & 1.46 & 1.59 \\
Variance & 0.0486 & 0.124 & 0.116 \\
& & & \\
Mean Absolute Deviation & 0 & 0.156 & 0.268 \\
\hline
\end{tabular}

Notes: The mean absolute deviation is relative to 1930A.

Table 2 shows that the mean tariff wedge prior to $\mathrm{SH}$ was equivalent to a $32 \%$ tariff on imported inputs. The SH legislative increase combined with deflation during 1930 increased the size of the mean tariff wedge to $46 \%$, and the subsequent deflation further increased it to $59 \%$ at the trough of imported prices in 1933. In addition to increasing the mean of the tariff wedges, the $\mathrm{SH}$ legislation also raised the cross-sectional variance of tariff rates substantially from $5 \%$ prior to $\mathrm{SH}$ to $12 \%$ in 1933.

\section{Aggregate Effects of the Tariff Structure}

The analysis of the previous section documented the wide range of sectoral distortions resulting from the SH tariff legislation and subsequent deflation. In this section we examine the impact of these distortions on aggregate consumption, employment, and welfare using the measures derived in Section 2.

The first exercise we conduct is to calculate the aggregate impact of protection using the tariff rate $\tau_{t} \equiv \tau_{t}\left(q_{t}\right)$ in time period $t$, which is calculated from (16) using the tariff schedule from period $t$ and evaluating the ad valorem equivalent of the specific tariffs using world prices at time $t$. We thus incorporate both legislated changes in tariff rates and price level induced changes in tariff rates for each period, which results in an increase in the the mean tariff rate from $30.8 \%$ in $1930 \mathrm{~A}$ to $45.7 \%$ in 1933 and an increase in the variance from 0.052 to 0.125 . In order to abstract from terms of trade changes, we solve for the equilibrium values assuming that prices remain constant at the 1930A levels, so that consumers and producers are assumed to be facing the tariff laden price vector $\tau_{t} q_{0}$ at $t .^{12}$

\footnotetext{
${ }^{12}$ The cost function parameters $\left(a_{0 d}, a_{0 V}, a_{0 m}\right)$ and $p_{V 0}$ are the values that satisfy the zero profit condition and match the cost shares $\left(\theta_{0 d}, \theta_{0 V}, \theta_{0 m}\right)$ from the input-output tables. The $\left(a_{j d}, a_{j V}, a_{j m}\right)$ are then solved to match the respective cost shares given $p_{V 0}$ for $j=1, . . N_{F}$. A similar procedure is used to solve for the $a_{c j}$ from the $\mu_{j}$ in the data.
} 
TABLE 3 - BENCHMARK CASE

\begin{tabular}{lccc}
\hline \hline Tariff Structure & $1930 \mathrm{~A}$ & $1930 \mathrm{~B}$ & 1933 \\
\hline Mean Tariff $(\tau-1)$ & 30.8 & 38.8 & 45.7 \\
Variance of Tariffs & 0.052 & 0.072 & 0.125 \\
Uniform Tariff Equivalent $(\tau-1)$ & 49.0 & 58.0 & 69.7 \\
Value added price: $\frac{p_{V}\left(\tau_{0}\left(q_{t}\right), q_{0}\right)}{p_{V}\left(1, q_{0}\right)}$ & -1.0 & -1.0 & -1.3 \\
Consumption price: $\frac{P_{C}\left(\tau_{0}\left(q_{t}\right), q_{0}\right)}{p_{V}\left(1, q_{0}\right)}$ & 1.2 & 1.4 & 1.5 \\
TFP $\left(\tau_{0}\left(q_{t}\right), q_{0}\right)$ & -1.2 & -1.4 & -1.7 \\
Employment: $\frac{L\left(\tau_{0}\left(q_{t}\right), q_{0}\right)}{L\left(1, q_{0}\right)}$ & 0.1 & 0.1 & 0.2 \\
Consumption: $\frac{C\left(\tau_{0}\left(q_{t}\right), q_{0}\right)}{C\left(1, q_{0}\right)}$ & -1.2 & -1.3 & -1.6 \\
Consumption Equivalent : $\frac{C^{E}\left(\tau_{0}\left(q_{t}\right), q_{0}\right)}{C\left(\tau_{0}\left(q_{t}\right), q_{0}\right)}$ & 1.2 & 1.4 & 1.7 \\
\hline
\end{tabular}

Note: Parameter values: $s=2, \gamma=2.5, \beta=.667$,

$\sigma_{M}=\sigma_{m}=3.5, \sigma_{C}=2.5, \sigma_{F}=1$.

Table 3 reports the values for some of the key the aggregate variables from the model, with each variable reported as a percentage change relative to its free trade variable Thus, the effect of the pre-SH tariffs is to reduce the return to domestic value added by about $1 \%$ relative to the free trade level. This is due to the fact that the pre-SH tariffs increased the price of importables to the production of exports by about $25 \%$, and these imports accounted for approximately $3 \%$ of the cost of the exportable good in the base period. Subsequent tariff increases due to SH and deflation had little impact on the return to value added. Similarly, the cost of the aggregate consumption bundle was about $1.2 \%$ higher in $1930 \mathrm{~A}$ due to the pre-SH tariffs, and increased an additional $0.3 \%$ due to SH. The third row in Table 3 shows that the aggregate effect of tariff protection on TFP at the peak of tariffs in 1933 was to reduce it by $1.7 \%$ relative to the free trade level. Note that almost $2 / 3$ of the effect of tariff protection on TFP was due to the pre-SH tariffs, with $\mathrm{SH}$ and the subsequent deflation reducing aggregate productivity by approximately $0.5 \%$ compared with the pre-SH level.

In order to calculate the effects on employment and consumption, we choose the utility function parameters $s=2$ and $\gamma=2.5$. These choices yield an intertemporal elasticity of substitution of 0.5 and a Frisch elasticity of labor supply of $2 / 3$, which are within the range of values obtained from micro studies. ${ }^{13}$ With these parameter choices, tariff protection leads to

\footnotetext{
${ }^{13}$ Chetty et al (2011) argue a Frisch elasticity of 0.75 is the upper bound of values that are consistent with
} 
a decrease in consumption of about $1.6 \%$ and an increase in employment of about $0.2 \%$. As noted in the discussion of (13), tariff protection will decrease consumption relative to free trade because reduction in TFP and $\frac{p_{V}}{P_{C}}$ both work to reduce consumption. The effects of these two changes on employment are conflicting, and with our chosen parameter values the net effect is a small increase in employment. ${ }^{14}$ The equivalent consumption effect indicates that at the peak of tariff protection, consumption would need to be increased by $1.7 \%$ to raise welfare to the free trade level. This is essentially equal to the TFP effect due to the minimal effect of protection on the level of employment. ${ }^{15}$

The comparison between the uniform tariff equivalent and the mean tariff shows that although the mean tariff was $45.7 \%$ at its peak, the effect of the tariff structure was equivalent to that of a uniform tariff of $69.7 \%$. The increase in the variance of tariffs thus had a significant effect in increasing the distortion associated with the protective structure as measured by the uniform tariff equivalent. However, as already noted it had a relatively small effect on the aggregate productivity and welfare measures.

How would the outcome have differed if Smoot Hawley had never been passed? We can address this question by solving the model using the effective tariff rates associated with the pre-SH tariff legislation for all three periods of the panel, $\tau_{0}\left(q_{t}\right)$. This exercise captures the effect of the decline in world prices on the effective tariff rate for goods that had specific tariffs under the pre SH legislation. As in the benchmark case, we assume world prices remain fixed at the initial level. The results for this counterfactual exercise on the aggregate measures are reported in Table 4. Since the pre-SH tariff included a number of specific tariff rates, the decline in prices still yielded an increase in the 1930B and 1933 cross sections that was about half that arising from the Smoot Hawley legislation as shown by the mean tariff rate. Interestingly, the variance of tariffs in 1933 would have been comparable to that under SH. As a result, the increase in the uniform tariff equivalent is almost $2 / 3$ of that occurring with $\mathrm{SH}$. The decline in TFP in the absence of SH would have been $1.5 \%$ relative to the free trade level, and the required consumption increase to compensate for the decline in tariff protection would have been $1.5 \%$ as well. These results indicate that if Smoot Hawley had not been passed, the increase in the tariff distortion would have been more than half of that which occurred under $\mathrm{SH}$, because deflation would have been responsible for a substantial increase in both the mean and dispersion of tariff rates.

micro. Elasiticities of intertemporal substitution in the range of 0.5 to 1 are typically obtained in studies using household data on consumption (eg. Attanasio, Banks, and Tanner (2002)).

${ }^{14}$ If we choose $s=1$ and $\gamma=1$, we obtain a small reduction in employment as a result of tariffs. However, the consumption equivalent is similar in this case.

${ }^{15}$ It can be shown that the measures reported in Table 3 are independent of the parameters $\nu, A$, and $K$. 
TABLE 4: NO SMOOT HAWLEY

\begin{tabular}{lccc}
\hline \hline & $1930 \mathrm{~A}$ & $1930 \mathrm{~B}$ & 1933 \\
\hline Mean Tariff $(\tau-1)$ & 30.8 & 33.1 & 38.4 \\
Variance of Tariffs & 0.052 & 0.072 & 0.125 \\
Uniform Tariff Equivalent $(\tau-1)$ & 49.0 & 55.0 & 61.6 \\
VA price: $\frac{p_{V}\left(\tau_{0}\left(q_{t}\right), q_{0}\right)}{p_{V}\left(1, q_{0}\right)}$ & -1.0 & -1.0 & -1.1 \\
Cons price: $\frac{P_{C}\left(\tau_{0}\left(q_{t}\right), q_{0}\right)}{p_{V}\left(1, q_{0}\right)}$ & 1.2 & 1.3 & 1.4 \\
TF P $\left(\tau_{0}\left(q_{t}\right), q_{0}\right)$ & -1.2 & -1.3 & -1.5 \\
Employment: $\frac{L\left(\tau_{0}\left(q_{t}\right), q_{0}\right)}{L\left(1, q_{0}\right)}$ & 0.1 & 0.1 & 0.2 \\
Consumption: $\frac{C\left(\tau_{0}\left(q_{t}\right), q_{0}\right)}{C\left(1, q_{0}\right)}$ & -1.2 & -1.3 & -1.4 \\
Consumption Equivalent $: \frac{C^{E}\left(\tau_{0}\left(q_{t}\right), q_{0}\right)}{C\left(\tau_{0}\left(q_{t}\right), q_{0}\right)}$ & 1.2 & 1.3 & 1.5 \\
\hline
\end{tabular}

Notes: Parameter values same as benchmark, Table 3.

In order to test the sensitivity of these results to our assumptions regarding the elasticities of substitution between domestic and imported goods, we also consider a case where we double the elasticities to $\sigma_{m}=\sigma_{M}=7$ and $\sigma_{C}=5$. The results for this exercise are reported in Table 5 . TFP now declines by $4.9 \%$ relative to free trade with the pre-SH tariffs with the higher substitution elasticities, which is more than 4 times that in the benchmark case. A larger elasticity of substitution leads to a substantially larger effect on TFP because of the greater substitution away from imported goods due to tariff protection. In addition to a larger effect on productivity, the higher elasticity also results in a substantially larger impact on employment, which now rises by $1.4 \%$. As a result of the increase in employment, the amount of consumption required to reach the free trade level $(5.6 \%)$ exceeds the TFP effect $(5.3 \%)$ in magnitude. The subsequent SH tariffs and deflation (1933) reduce TFP by an additional $0.4 \%$ relative to the free trade level. Finally, we note that increasing the elasticity of substitution between importables also has the effect of increasing the uniform tariff equivalent of the tariff structure. The greater substitution elasticities raise the distortion associated with variance in the tariff structure, and thus tends to raise the uniform tariff equivalent. 
TABLE 5 - DOUBLE SUBSTITUTION ELASTICITIES

\begin{tabular}{lccc}
\hline \hline Uniform Tariff Equivalent $(\tau-1)$ & 56.5 & 62.5 & 68.8 \\
VA price: $\frac{p_{V}\left(\tau_{t}, q_{0}\right)}{p_{V}\left(1, q_{0}\right)}-1$ & -2.9 & -2.7 & -2.9 \\
Cons. price: $\frac{P_{C}\left(\tau_{t}, q_{0}\right)}{P_{C}\left(1, q_{0}\right)}-1$ & 2.8 & 3.1 & 3.0 \\
$T F P\left(\tau_{t}, q_{0}\right)-1$ & -4.9 & -5.1 & -5.3 \\
Employment: $\frac{L\left(\tau_{t}, q_{0}\right)}{L\left(1, q_{0}\right)}-1$ & 1.4 & 1.5 & 1.6 \\
Consumption: $\frac{C\left(\tau_{t}, q_{0}\right)}{C\left(1, q_{0}\right)}-1$ & -4.0 & -5.1 & -5.3 \\
Consumption Equivalent $: \frac{C^{E}\left(\tau_{t}, q_{0}\right)}{C\left(\tau_{t}, q_{0}\right)}$ & 5.2 & 5.4 & 5.6 \\
\hline Parameter values: $\sigma_{C}=5, \sigma_{m}=\sigma_{M}=7$, rest as in benchmark
\end{tabular}

FIGURE 5 - TFP EFFECTS, SENSITIVITY ANALYSIS

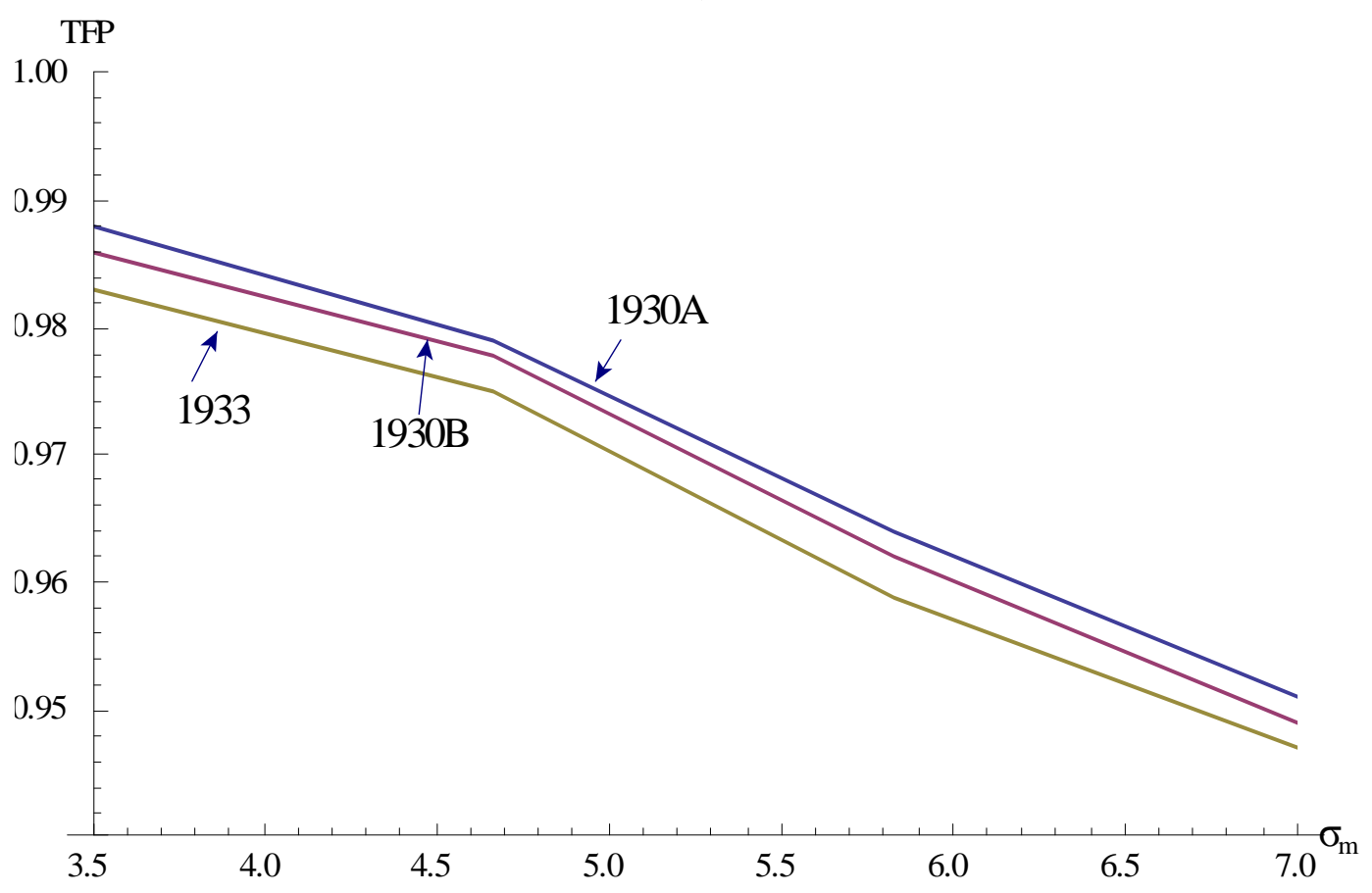

Note: Each line show the TFP effects (relative to free trade of 1) as the elasticity of substitution rises for each year of our panel. 
These results suggest that the aggregate cost of tariff protection can be fairly sensitive to the assumptions made regarding $\sigma_{m}$ and $\sigma_{C}$. Figure 5 shows how the loss in TFP varies with the value of the substitution elasticities for each of the cross sections we analyze, with elasticities $\left(\sigma_{m}, \sigma_{M}, \sigma_{C}\right)$ evaluated at $1,4 / 3,5 / 3$ and 2 times their benchmark values For each cross section, the magnitude of the total loss from tariff protection relative to free trade is non-linear in the substitution elasticity. Interestingly, however, the incremental loss moving from 1930A to 1933 due to the SH tariffs is in the $0.4-0.5 \%$ range for all of the elasticity values. Thus, the incremental impact of $\mathrm{SH}$ is quite robust to the elasticity assumption in this range.

\section{TABLE 6 - DOUBLE ALL IMPORT SHARES}

\begin{tabular}{lccc}
\hline \hline Uniform Tariff Equivalent & $1930 \mathrm{~A}$ & $1930 \mathrm{~B}$ & 1933 \\
\hline VA price: $\frac{p_{V}\left(\tau_{t}, q_{0}\right)}{p_{V}\left(1, q_{0}\right)}$ & 47.4 & 55.7 & 67.7 \\
Cons. price: $\frac{P_{C}\left(\tau_{t}, q_{0}\right)}{P_{C}\left(1, q_{0}\right)}$ & -2.6 & -2.7 & -3.3 \\
TFP $\left(\tau_{t}, q_{0}\right)$ & 2.2 & 2.6 & 2.6 \\
Employment: $\frac{L\left(\tau_{t}, q_{0}\right)}{L\left(1, q_{0}\right)}$ & -2.5 & -3.0 & -3.6 \\
Consumption: $\frac{C\left(\tau_{t}, q_{0}\right)}{C\left(1, q_{0}\right)}$ & 0.1 & 0.2 & 0.5 \\
Consumption Equivalent $: \frac{C^{E}\left(\tau_{t}, q_{0}\right)}{C\left(\tau_{t}, q_{0}\right)}$ & 2.6 & 3.1 & 3.8 \\
\hline
\end{tabular}

Notes: Parameter values same as benchmark, Table 3.

As a final exercise, we consider the impact of a doubling of the US import share using the benchmark elasticity assumptions. That imports were a small fraction of GDP is one factor in explaining why the aggregate impact of tariff protection is relatively small in our benchmark case. The raises the question of how large import shares must be in order to have significant effects on aggregate productivity and welfare. Table 6 considers a counterfactual exercise of doubling the US import share from its 1930 levels. This change has the effect of doubling the impact of tariffs on the price of value added. The effect of the pre SH tariffs on TFP is approximately double that in the benchmark case, since TFP now decreases by $2.5 \%$ from the pre SH tariffs. Doubling the import share also doubles the percentage increase in consumption required to compensate for the effect of the tariff structure relative to free trade. Employment effects continue to be quite small in this case. Note that although the aggregate effects are increased substantially in this counterfactual, there is only a minor effect on the uniform tariff 
equivalent. This is because the uniform tariff equivalent captures the effect of tariffs on one import category relative to another. Doubling the import volume increases the effects on all import categories proportionally, and thus has a minimal effect on this aggregate measure.

\section{Conclusions}

We have constructed a panel of tariff lines to quantify the effect of the Smoot Hawley tariff legislation on the mean and dispersion of tariff rates. The panel shows that the mean effective tariff rate increased from $31 \%$ to $46 \%$ between 1930 and 1933, and that the variance of tariff rates at the tariff line level more than doubled over the same period. We also used this panel to construct tariff wedges reflecting the increased price of imported materials for domestic production sectors. The mean of these wedges increased from $32 \%$ to $59 \%$, and the variance more than doubled. The role of dispersion on tariff rates was captured by the fact that the uniform tariff rate equivalent exceeded the average tariff rate by $18 \%$ under the pre-SH tariffs in 1930, and this differential increased to $24 \%$ by 1933 . This result showed that the tariff structure was substantially more distorting than suggested by the average tariff rate, and the increased variance in tariff rates from $\mathrm{SH}$ raised the differential between the uniform tariff equivalent and the average tariff.

Although our tariff line analysis indicated the existence of substantial sectoral distortions, our general equilibrium model indicated that the impact of these distortions at the aggregate level was relatively modest in the benchmark parameterization. The pre-SH tariff protection reduced TFP by $1.1 \%$ relative to free trade, and the $\mathrm{SH}$ legislation was responsible for a further 0.5\% decline in TFP We also showed that if SH had not been passed, the presence of specific tariffs in the existing tariff legislation would have reduced TFP by $0.3 \%$ between 1930 and 1933 due to declining world prices. This conclusion is consistent with previous findings of Crucini (1994) and Irwin (1998) that deflation was responsible for a significant portion of the increase in effective tariff rates that occurred following the passage of the SH legislation.

Two caveats should be kept in mind in interpreting our results on the aggregate effects of the SH tariffs. First, the aggregate effects could be larger if the true substitution elasticities are larger than the ones used in our benchmark analysis. Our counterfactual exercise showed that a doubling of the elasticities of substitution led to a quadrupling of the effect of pre-SH tariffs on TFP. In addition, larger elasticities resulted in more significant effects on labor markets. Note however, that the incremental effect of the SH legislation and decline in world prices on TFP from 1930-1933 was quite robust across the different elasticity assumptions. This suggests the value of investigating the tariff policies over the interwar era to better capture the aggregate impacts of commercial policy during the Great Depression.

Second, we assume that tariffs have no effect on world prices. Such an assumption is appropriate when the country in question is a small country, or when retaliation by foreign countries 
offsets any effects of tariffs on the terms of trade. The existence of a favorable terms of trade effect for the tariff imposing country would reduce the magnitude of the loss in productivity, or could even lead to a higher productivity level. However, our data did not suggest the presence of significant reductions in world prices as a result of the Smoot Hawley tariffs.

Our analysis could also be extended to incorporate additional effects of tariff protection. For example, our analysis does not incorporate the effects of tariff protection on capital accumulation. Crucini and Kahn (1996) find that persistent tariff protection can reduce capital accumulation, which would lead to a larger aggregate effect of tariff protection. Finally, tariff protection could lead to larger effects on productivity if it leads firms to increase markups. Such an outcome could occur if firms are imperfectly competitive and tariff protection makes firm demand curves less elastic, or if protection facilitates the formation of cartels. These represent areas for future work. 


\section{References}

[1] Anderson, James and Peter Neary. 2005. Measuring the Restrictiveness of International Trade Policy, MIT Press (Cambridge).

[2] Chetty, Raj, Adam Guren, Day Manoli and Andrea Weber, "Are Micro and Macro Labor Elasticities Consistent? A Review of the Evidence on Intensive and Extensive Margins," American Economic Review Papers and Proceedings,

[3] Crucini, Mario J. 1994. "Sources of Variation in Real Tariff Rates: The United States, 1900-1940. American Economic Review, 84(3), 732-743.

[4] Crucini, Mario J. and James Kahn. 1996. "Tariffs and Aggregate Economic Activity: Lessons From the Great Depression. Journal of Monetary Economics, 38(3), 427-467.

[5] Eaton, Jonathan and Samuel Kortum. 2002. "Technology, Geography, and Trade," Econometrica, 70 (5), 1741-79.

[6] Hsieh, Chiang-ti and Peter Klenow (2009), "Misallocation and Manufacturing TFP in India and China," Quarterly Journal of Economics, 124 (4), 1403-48.

[7] Irwin, Douglas. 1998. "Changes in US Tariffs: The Role of Import Prices and Commercial Policy," American Economic Review, 88 (4), 1015-26.Irwin, Douglas. 1998a. "Changes in US Tariffs: The Role of Import Prices and Commercial Policy," American Economic Review, 88 (4), 1015-26.

[8] Irwin, Douglas. 1998b. "The Smoot Hawley Tariff: A Quantitative Assessment," Review of Economics and Statistics, 89, 326-34.

[9] Irwin, Douglas. 2011. Peddling Protectionism: Smoot Hawley and the Great Depression, Princeton University Press (Princeton).

[10] Restuccia, Diego and Richard Rogerson (2008), "Policy Distortions and Aggregate Productivity with Heterogeneous Establishments," Review of Economic Dynamics, 11, 707-20.

[11] Leontief, Wassily W. 1941. The Structure of the American Economy. Oxford University Press.

[12] Simonovska, and Michael Waugh. 2011. "The Elasticity of Trade: Evidence and Estimates," CESifo working paper series no. 3356.

[13] Taussig, F. W. 1931. The Tariff History of the United States, Putnam (New York). 


\section{Appendix A}

The matching algorithm takes two arrays of text descriptions as inputs. The output is a matrix of scores in which the $i j$ th element is a number between zero and 1 for the quality of a match between row $i$ from the first data set and row $j$ from the second. A score of 1 means that the text descriptions are identical and a score of zero means they have no characters in common. Figure A.1 shows the number of matches as a function of the quality of the match. Beginning with a minimum threshold of 0.8 , the number of matches is 1,800 and fall to about 1,690 where the match is for all intents and purposes 'perfect.'

FIGURE A.1 - MATCHING ALGORITHM EXAMPLE, 1930

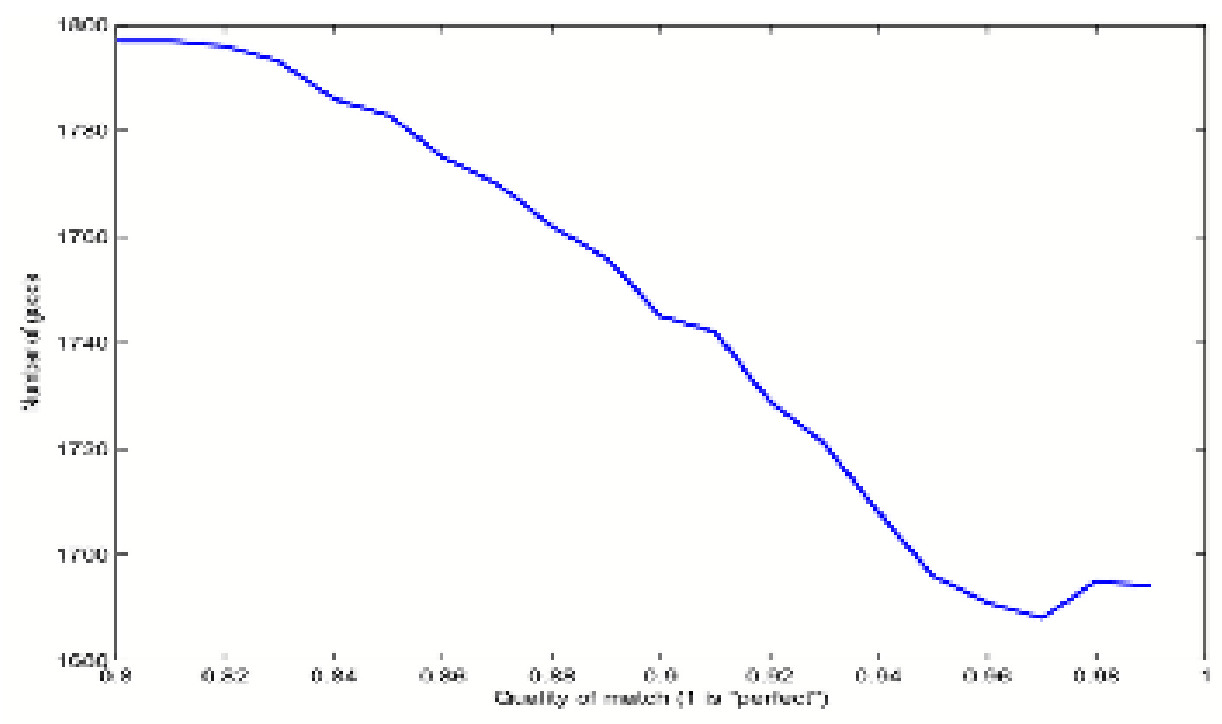

While the matching algorithm is an invaluable tool, it does not resolve the issue of eight scenarios involving line-item splitting, aggregation or reorganization across periods. For example, our matching procedure does not rule out more than one 1930A line item being matched to the same 1930B (or 1933) line item. We must account for this type of aggregation in the data. To do this we collect the set all best matches which are connected to each other through one or more line item aggregations. We then construct an aggregated line item series by creating a weighted average of the individual line items where the $1930 \mathrm{~A}$ import values are used as weights. After completing the construction of a balanced panel, the size of our cross-section shrinks to 495 line items. This occurs for two reasons. First, aggregation naturally reduces the number of individual tariff lines and due to a large degree of re-organization between 1930A and 1930B/1933; it is common for two or line items to be matched to the same line item in a later cross-section. Second, aggregation exacerbates missing data issues. Any set of line items which is matched to any individual observation with missing data have to be discarded since the aggregation cannot be performed. 
TABLE A1 - MOMENTS OF SOURCE DATA AND BALANCED PANEL

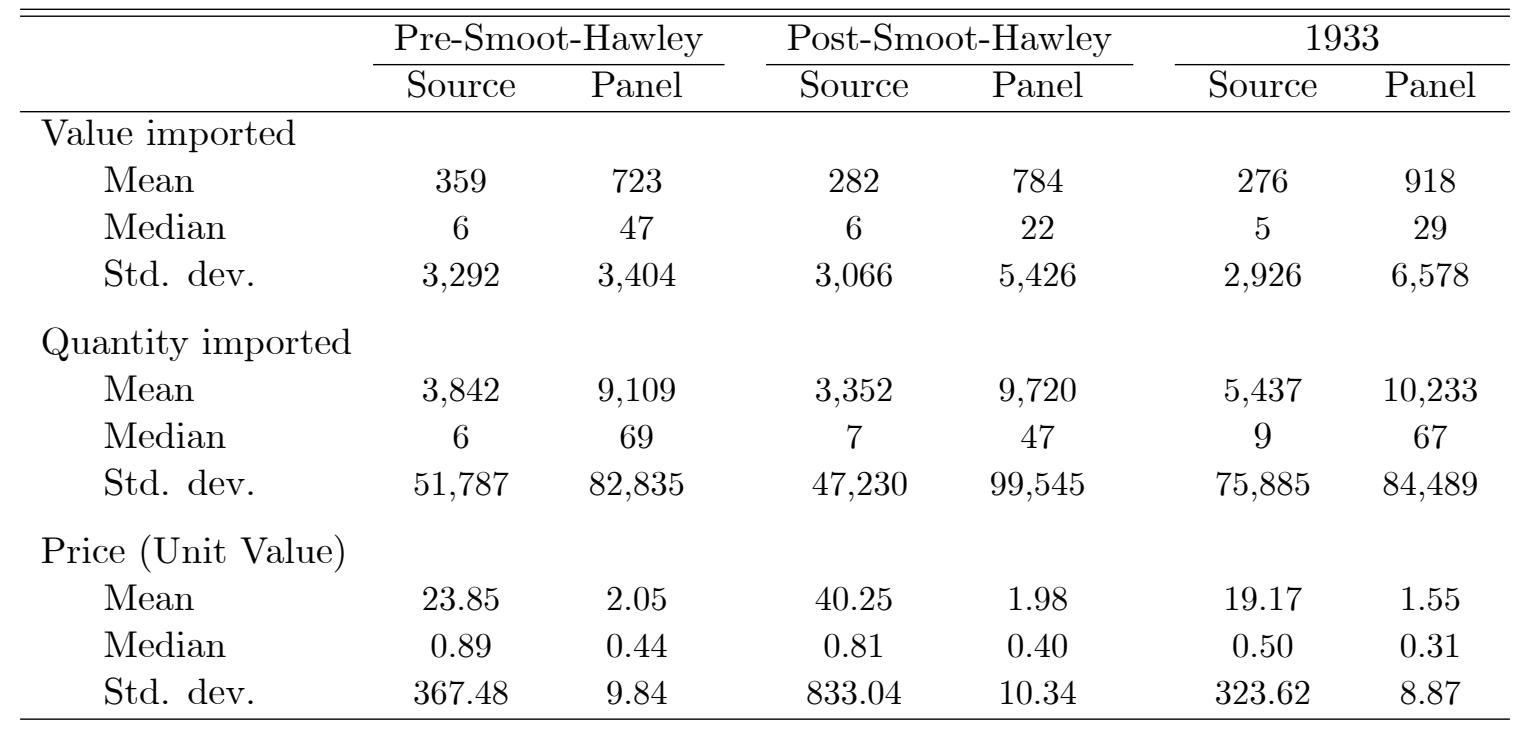

